\title{
\& chamaneme \\ Matrine exhibits antiviral activity in a PRRSV/PCV2 co-infected mouse model
}

$\mathrm{Na}$ Sun

Shanxi Agricultural University

Hua Zhang

Shanxi Agricultural University

Panpan Sun

Shanxi Agricultural University

Ajab Khan

Shanxi Agricultural University

Jianhua Guo

Texas A\&M University

Xiaozhong Zheng

The University of Edinburgh

Yaogui Sun

Shanxi Agricultural University

Kuohai Fan

Shanxi Agricultural University

Wei Yin

Shanxi Agricultural University

Hongquan Li ( $\sim$ livets@163.com )

\section{Research}

Keywords: Matrine, PRRSV/PCV2 co-infection, mouse model, interstitial pneumonia, immune function

Posted Date: May 6th, 2020

DOl: https://doi.org/10.21203/rs.3.rs-25795/v1

License: (c) (1) This work is licensed under a Creative Commons Attribution 4.0 International License. Read Full License

Version of Record: A version of this preprint was published at Phytomedicine on October 1st, 2020. See the published version at https://doi.org/10.1016/j.phymed.2020.153289. 


\section{Abstract}

\section{Background}

PRRSV and PCV2 co-infection is very common in swine industry which results in huge economic losses worldwide. Although vaccination is used to prevent viral diseases, immunosuppression induced by PRRSV and PCV2 leads to vaccine failure. Our previous results have demonstrated that Matrine possessed antiviral activities against PRRSV/PCV2 co-infection in vitro. To establish a PRRSV/PCV2 coinfected KM mouse model and evaluate the antiviral activities of Matrine against PRRSV/PCV2 coinfection. A total of $144 \mathrm{KM}$ mice were randomly divided into six groups with 24 mice in each group, named as: normal control, PRRSV/PCV2 co-infected group (PRRSV/PCV2 group), Ribavirin treatment positive control (Ribavirin control) and Matrine treatment groups (Matrine $40 \mathrm{mg} / \mathrm{kg}$, Matrine $20 \mathrm{mg} / \mathrm{kg}$ and Matrine $10 \mathrm{mg} / \mathrm{kg}$ ). Except normal control group, all mice in other five groups were inoculated with PRRSV, followed by PCV2 at $2 \mathrm{~h}$ later. At 7 days post-infection (dpi), mice in the treatment groups were intraperitoneally administered with various doses of Matrine and Ribavirin, twice a day for 5 consecutive days.

Results

PRRSV N and PCV2 CAP genes were detected by PCR in multiple tissues including heart, liver, spleen, lungs, kidneys, thymus and inguinal lymph nodes. The viral load of PCV2 was the highest in liver followed by thymus and spleen. Although PRRSV were detected in most of the tissues, but the replication of PRRSV was not significantly increased, as shown by qPCR analysis. Comparing with PCV2 infection alone, PRRSV infection significantly elevated PCV2 replication and also exacerbated PCV2 induced interstitial pneumonia. qPCR analysis demonstrated that $40 \mathrm{mg} / \mathrm{ml}$ Matrine significantly attenuated PCV2 replication in liver and alleviated virus induced interstitial pneumonia, suggesting that Matrine could directly inhibit virus replication. In addition, Matrine treatment enhanced peritoneal macrophages phagocytosis at 13 and $16 \mathrm{dpi}$, and $40 \mathrm{mg} / \mathrm{kg}$ of Matrine increased the proliferation activity of lymphocytes. Body weight gain was continuously promoted by administrating Matrine at $10 \mathrm{mg} / \mathrm{kg}$.

\section{Conclusion}

Matrine possessed antiviral activities via inhibiting virus replication and regulating immune functions in mice co-infected by PRRSV/PCV2. These data provide new insight into controlling PRRSV and PCV2 infection and support further the research for developing Matrine as a new possible veterinary medicine.

\section{Background}

Co-infections involving porcine reproductive and respiratory syndrome virus (PRRSV) and porcine circovirus type 2 (PCV2) are still common world-widely in pig industry and has resulted in enormously economic losses. The co-infection status of four important swine viruses (classical swine fever virus, PRRSV, PCV2 and PCV3) in 159 diseased and dead pigs in eight regions of China from 2016 to 2018 was 
evaluated by Chen et al (2019), demonstrated that co-infection is a common phenomenon and the percentage of PRRSV and PCV2 co-infection is the highest among them [1]. Vaccination is usually used to prevent and control viral diseases. Although there are several vaccines available, vaccines are not highly effective against PRRSV/PCV2 co-infection due to high mutation rate of PRRSV and PCV2 viruses as well as the complicated co-infection status. A trivalent vaccine against $\mathrm{M}$. hyopneumoniae, PCV2, and PRRSV, licensed in many Asian countries did not provide the same protection as each respective monovalent vaccine [2]. Vaccination with PRRS modified live virus vaccine followed by challenge with PRRSV and PCV2, provide protection for PRRSV but enhances PCV2 replication and pathogenesis [3]. Therefore, these problems highlight the need for alternative approaches to control this disease.

Screening of antiviral natural compounds extracted from traditional Chinese medicines is gaining attentions in the world. Many natural compounds have the antiviral activity against African swine fever virus [4], H1N1 [5], porcine parvovirus [6], infectious bursal disease virus [7] and Marek's disease virus [8, 9]. Ginsenoside Rg1 [10], Sodium tanshinone IIA sulfonate [11], tea seed saponins [12], Dipotassium Glycyrrhetate [13] and Xanthohumol [14] were selected as a potential drug candidate to treat PRRS. Polysaccharide of Sargassum weizhouense [15], Epigallocatechin Gallate [16], saponins [17] and Astragalus polysaccharides [18] inhibit PCV2 replication in vitro and in mice. Matrine, a compound extracted from sophora flavescens Ait., possess anti-PRRSV [19], anti-PCV2 [20] and anti-PPRSV/PCV2 co-infection activity in vitro, demonstrated in our previous studies [21].

Undoubtedly an appropriate laboratory animal model is important for drug development. Due to easy handling and low price, mouse model is a better choice for preliminary drug screening. It has been reported that PRRSV does not replicate in rodents [22], but PCV2 infection was successfully established by multiple routs including intranasal, intraperitoneal, oral and intramuscular injection [23-26]. Piglets have been used for PRRSV and PCV2 co-infection model [27, 28], but there are few literatures on the mouse model for PRRSV and PCV2 co-infection.

In this study, mouse model co-infected by PRRSV and PCV2 was firstly established, which was used to further evaluate the antiviral activities of Matrine against PRRSV and PCV2 co-infection.

\section{Methods}

\section{Compounds, viruses and KM mice}

Matrine was purchased from Nanjing Zelang Meditech Ltd, China and its purity was $98 \%$ by HPLC. Ribavirin solution for injection ( $1 \mathrm{ml}: 0.1 \mathrm{~g})$ was purchased from Shanxi Taiyuan Pharmaceutical Co., Ltd, China. The titers of PRRSV and PCV2 were $10^{7.5} \mathrm{TCID}_{50} / \mathrm{ml}$ and $10^{5.15} \mathrm{TCID}_{50} / \mathrm{ml}$, respectively by Immunofluorescence assay on PAM cells. ${ }^{1} 0^{6} \mathrm{TCID}_{50} / \mathrm{ml} \mathrm{PRRSV}$ and $10^{4} \mathrm{TCID}_{50} / \mathrm{ml} \mathrm{PCV} 2$ were used in this experiment [21]. All mice used in this study were purchased from the Experimental Animal Center, Academy of Military Medical Sciences, Beijing, China, and were humanely managed according to the established guidelines of ethics committee of Shanxi Agriculture University. 


\section{Establishment of KM mouse model co-infected by PRRSV/PCV2}

6-week-old KM mice were randomly divided into three groups with 6 in each group. The group inoculated with normal saline was named as an uninfected control group, with PRRSV first followed by PCV2 $2 \mathrm{~h}$ later as PRRSV/PCV2 co-infected group and PCV2 only as PCV2 infected group. The inoculation routes and dose of both PRRSV and PCV2 were as followed: each mouse was respectively inoculated $0.5 \mathrm{ml}$ intraperitoneally, $0.3 \mathrm{ml}$ subcutaneously on back and $0.05 \mathrm{ml}$ intranasally. At 7 days post-infection (dpi), samples of heart, liver, spleen, lungs, kidneys, thymus and inguinal lymph nodes were respectively collected and frozen at $-80^{\circ} \mathrm{C}$ for detecting PRRSV and PCV2 by PCR. The samples of lungs were also fixed in Bouin's solution for the histopathological observation.

\section{Experimental design}

144 Kunming mice were randomly divided into six groups with 24 mice in each group: normal control, PRRSV/PCV2 co-infected group (PRRSV/PCV2 group), Ribavirin treatment positive control (Ribavirin control), Matrine treatment groups (Matrine $40 \mathrm{mg} / \mathrm{kg}$, Matrine $20 \mathrm{mg} / \mathrm{kg}$ and Matrine $10 \mathrm{mg} / \mathrm{kg}$ ). Selected doses of Matrine $(40,20$ and $10 \mathrm{mg} / \mathrm{kg}$ ) used in these experiments were determined by Acute toxicity test (data were not shown). Except for normal control group, animals in all other groups were inoculated with PRRSV followed by PCV2 $2 \mathrm{~h}$ later, as described in the section of model establishment. At $7 \mathrm{dpi}$, mice in the treatment groups were intraperitoneally administered with various doses of Matrine and Ribavirin, twice a day for 5 days at a dose of $0.2 \mathrm{ml}$ Matrine or Ribavirin per $10 \mathrm{~g}$ body weight each time. Mice in the control group were administered with the same volume of normal saline at the same frequency and by the same route. The body weight of mice in each group before virus infection and at 10, 13, 16 and $19 \mathrm{dpi}$ were recorded. Six mice of each group were sacrificed at 10,13,16 and $19 \mathrm{dpi}$, and the spleen and thymus were weighed and their immune organ indices were calculated according to the following formula: the index of organ $(\mathrm{mg} / \mathrm{g})$ = weight of organ / body weight.

\section{Quantification of PCV2 DNA in liver tissues}

At 10,13, 16 and $19 \mathrm{dpi}$, liver of six mice in each group was collected and stored in liquid nitrogen. After grinding with liquid nitrogen, DNA of liver tissue was extracted using TIANamp Genomic DNA Kit (TIANGEN, China). The concentration of DNA was measured using NanoDrop 1000 spectophotometer (NanoDrop Technologies, Wilmington, DE, USA). A 148 bp fragments from the CAP gene of PCV2 was amplified with specific forward primer 5'-GTCTACATTTCCAGCAGTTTG-3' and reverse primer 5'CTCCCGCCATACCATAA-3'. Real time PCR was performed using Applied Biosystems ${ }^{\circledR} 7500$ Real-Time PCR system, and carried out with 2×SYBR Green qPCR Master Mix from Bimake according to the manufacturer's instructions. A recombinant plasmid vector containing PCV2 CAP gene fragment was used to generate a standard curve.

\section{Measurement of phagocytosis of peritoneal macrophages}


Phagocytosis of peritoneal macrophages were measured as a cellular uptake of FITC-dextran and quantified by flow cytometry as described by Xiu et al [29]. Briefly, peritoneal macrophages were aseptically collected and resuspended in $1 \mathrm{ml}$ RPMI 1640 medium. $0.2 \mathrm{mg} / \mathrm{ml}$ FITC-dextran was added into each tube and incubated for $30 \mathrm{~min}$ at $37^{\circ} \mathrm{C}$. Cells added with the same amount of FITC-dextran and incubated at $4^{\circ} \mathrm{C}$ for 30 min were used as a baseline for macrophages phagocytosis assay. All cells were then collected and stained with APC-conjugated anti-F4/80 antibody and PE-conjugated anti-CD11b antibody for 20 min at room temperature in dark. Phagocytic ability was evaluated using Median

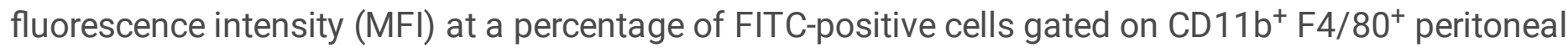
macrophage.

\section{Lymphocytes proliferation assay using CFSE labeling}

Murine splenic lymphocytes were collected using lymphocyte separation medium (TBD, China). Lymphocyte proliferation was determined using CFSE labeling by flow cytometry as described by Wang [30]. $500 \mu \mathrm{l}$ CFSE with a concentration of $4 \mu \mathrm{M}$ was added into the same amount of lymphocytes suspension in PBS. After incubation at $37^{\circ} \mathrm{C}$ for 10 min with slight shaking, $5 \mathrm{ml}$ PBS supplemented with $10 \%$ fetal calf serum (FCS) was added and then incubated for $5 \mathrm{~min}$ on ice to stop the dying process. The CFSE-labelled cells were placed in 24-well plates with a density of $4 \times 10^{6} / \mathrm{ml}$ and incubated in the culture medium supplemented with ConA (the final concentration was $5 \mu \mathrm{g} / \mathrm{ml}$ ) or LPS (the final concentration was $20 \mu \mathrm{g} / \mathrm{ml}$ ). The cells were cultured for $48 \mathrm{~h}$ at $37^{\circ} \mathrm{C}$ and then analyzed by flow cytometry.

\section{Statistical analyses}

All the data were expressed as mean \pm standard errors of the mean (SEM) and the statistical analysis were performed using SPSS version 21.0 software (SPSS, Chicago, IL, USA). A one-way analysis of variance (ANOVA) followed by LSD was used to analyze the results. When the Test of Homogeneity of Variances was lower than 0.05 , Mann-Whitney U-test (nonparametric test) was used for statistical analysis. Histograms were obtained from GraphPad Prism version 5 (GraphPad software, San Diego, CA). * means $\mathrm{P}<0.05, * *$ means $\mathrm{P}<0.01$, *** means $\mathrm{P}<0.001$.

\section{Results}

\section{Distribution of PRRSV and PCV2 in different organs}

At 7 dpi of PRRSV and PCV2, tissues of inguinal lymph nodes, spleen, liver, heart, lungs, kidneys and thymus were collected to determine the distribution of PRRSV and PCV2 by PCR to amplify a $196 \mathrm{bp}$ fragment of PRRSV N gene and 148 bp fragment of PCV2 CAP. Both PRRSV N gene (Fig. 1A) and PCV2 CAP gene (Fig. 1B) were detected in all tissues collected above. As shown in Table 1, only one in five mice was positive for PRRSV in inguinal lymph node while PRRSV was detected in all other tissues collected from 5 mice. For PCV2 CAP gene, at least three mice were positive in the tissues collected from 6 mice. According to the PCR results, both PRRSV and PCV2 transmitted to most of the collected mice tissues. 
Table 1

The tissue distribution of PRRSV and PCV2 in co-infected mice by PCR

\begin{tabular}{|c|c|c|c|c|c|c|c|c|}
\hline & \multirow{2}{*}{$\begin{array}{l}\text { \#of positive } \\
\text { mice }\end{array}$} & \multicolumn{7}{|c|}{ \#of positive tissues } \\
\hline & & $\begin{array}{l}\text { Inguinal lymph } \\
\text { nodes }\end{array}$ & Lung & Liver & Spleen & Kidney & Heart & Thymus \\
\hline PRRSV & $5 / 5$ & $1 / 5$ & $5 / 5$ & $5 / 5$ & $5 / 5$ & $5 / 5$ & $5 / 5$ & $5 / 5$ \\
\hline PCV2 & $6 / 6$ & $5 / 6$ & $5 / 6$ & $6 / 6$ & $5 / 6$ & $3 / 6$ & $6 / 6$ & $5 / 6$ \\
\hline
\end{tabular}

\section{PRRSV infection enhanced PCV2 replication and induced more severe lung lesions}

At $7 \mathrm{dpi}$, PCV2 CAP gene copy numbers were the highest in liver, followed by thymus and spleen as shown in Fig. 1C. These results were similar both in PRRSV/PCV2 co-infected and PCV2 infected groups, suggesting that PCV2 has tissue tropism in mouse model. Furthermore, the results showed that PCV2 CAP gene copies in liver $(p<0.05)$, thymus $(p>0.05)$ and spleen $(p<0.01)$ of PRRSV/PCV2 co-infected mice were significantly higher than PCV2 infected mice, indicating PRRSV infection enhanced PCV2 infection in mouse model. In addition, compared with normal control group, obvious lung lesions were observed in both PRRSV/PCV2 co-infected and PCV2 infected mice (Fig. 2A). Particularly, the hemorrhagic area was larger in PRRSV/PCV2 co-infected mice than PCV2 infected mice. H\&E staining of lungs (Fig. 2B) revealed that both PRRSV/PCV2 co-infected and PCV2 infected mice displayed typical characteristics of interstitial pneumonia including thickened alveoli septa and decreased alveolar area. Taken all these histopathological observations, the lesions of lungs were more severe in PRRSV/PCV2 coinfected mice, suggesting that PRRSV infection enhanced PCV2 induced lungs lesions.

\section{Matrine restrained PCV2 replication in liver and alleviated lungs lesions induced by virus infection}

PCV2 CAP gene copy numbers in liver were measured by qPCR as shown in Fig. 3A. At $10 \mathrm{dpi}$, compared with virus control group, the CAP gene copies were significantly decreased in Matrine $40 \mathrm{mg} / \mathrm{kg}$ treatment group $(p<0.01)$. The CAP gene in Ribavirin treatment group was lower but no significant difference was observed ( $p>0.05)$. At $13 \mathrm{dpi}$, CAP gene copies in Ribavirin $(p<0.01)$, Matrine $40 \mathrm{mg} / \mathrm{kg}(p<0.05)$ and $20 \mathrm{mg} / \mathrm{kg}(p<0.05)$ treatment groups were significantly lowered than that in virus control. Compared with virus control at 16 and $19 \mathrm{dpi}$, CAP gene copies were decreased in drug treatment groups but without statistical difference $(p>0.05)$. Compared with normal control, the lungs of PRRSV/PCV2 co-infected mice displayed typical characteristics of interstitial pneumonia including thickened alveoli septa and decreased alveolar area. However, both Ribavirin and Matrine treatments (especially 40 and $20 \mathrm{mg} / \mathrm{kg}$ ) could significantly alleviated these pathological changes as shown in Fig. 3B.

\section{Measurement of body weight gain, spleen and thymus indices in different treatments}

Compared with normal control, the body weight gain in PRRSV/PCV2 group was significantly declined at $19 \mathrm{dpi}(\mathrm{p}<0.01)$, while increased with varying degrees in Ribavirin and Matrine treatments, especially Matrine $10 \mathrm{mg} / \mathrm{kg}$ treatment group $(p<0.001)$ as shown in Fig. 4A. Moreover, the body weight gain in 
Matrine $10 \mathrm{mg} / \mathrm{kg}$ was higher at each indicated time point: $10(\mathrm{p}>0.05), 13(\mathrm{p}<0.01)$ and $16 \mathrm{dpi}(\mathrm{p}<$ $0.05)$, suggesting that Matrine has an effect of gaining body weight with the dose of $10 \mathrm{mg} / \mathrm{kg}$. The spleen index in PRRSV/PCV2 group was much higher than that in normal control at $10(p<0.01), 13(p<$ $0.05), 16(p=0.067)$ and $19(p<0.05)$ dpi. However, at 13 dpi, Matrine with the dose of $40(p<0.05)$ and $10(p<0.05) \mathrm{mg} / \mathrm{kg}$ significantly decreased the spleen index induced by virus infection (Fig. 4B). As shown in Fig. 4C, compared with normal control, the thymus index in PRRSV/PCV2 group was significantly higher both at $10(p<0.01)$ and $13(p<0.01)$ dpi and there were no remarkable changes at 16 and 19 dpi. Meanwhile, both Ribavirin and Martine declined the increasing trend with varying degrees.

\section{Matrine Regulate Peritoneal Macrophages Phagocytosis}

Phagocytic ability of peritoneal macrophages was evaluated using MFI at the percentage of FITC-positive cells gated on $\mathrm{F} 4 / 80^{+} / \mathrm{CD} 11 \mathrm{~b}^{+}$cells. As shown in Fig. $5 \mathrm{~A}$ and $\mathrm{B}$, at $10 \mathrm{dpi}$, the MFI and the ratio of $\mathrm{F} 4 / 80^{+} / \mathrm{CD} 11 \mathrm{~b}^{+}$in PRRSV/PCV2 group was significantly higher than that of normal control $(p<0.01)$. These results indicated that virus infection promoted an increase in macrophages and enhanced their phagocytic ability. Compared with PRRSV/PCV2 group, the percentage of F4/80 $/ C D 11 b^{+}$in Ribavirin and Matrine treatment groups were not changed significantly, while the MFI in these groups were remarkable decreased $(p<0.01)$. In addition, at 13 and $16 \mathrm{dpi}$, the MFI in PRRSV/PCV2 group was much lowered than that in normal control which means that there were no remarkable changes in macrophages, indicating that persistent infection of virus has leaded to the decrease of the phagocytic ability of macrophages. However, Matrine with the dose of 40 and $20 \mathrm{mg} / \mathrm{kg}$ has promoted the phagocytic ability of macrophages compared with PRRSV/PCV2 group.

\section{Effects Of Matrine On The Proliferation Of Splenic Lymphocytes}

At $10 \mathrm{dpi}$, the proliferation index of splenic lymphocytes with and without mitogen stimulus in PRRSV/PCV2 group was remarkably higher compared with the normal control, while it decreased in Ribavirin both with and without LPS stimulus compared with PRRSV/PCV2 group $(p<0.05)$. Moreover, the proliferation indices in Matrine 40 and $10 \mathrm{mg} / \mathrm{kg}$ treatment groups stimulated with both ConA and LPS were much lowered than those in PRRSV/PCV2 group as shown in Fig. 6. In addition, at $16 \mathrm{dpi}$, Matrine with a dose of $40 \mathrm{mg} / \mathrm{kg}$ enhanced the proliferation index with and without mitogen stimulus compared with PRRSV/PCV2 group. The proliferation index showed no-significant changes among all the groups at $19 \mathrm{dpi}$.

\section{Discussion}

Fan et al have clarified the synergistic effects of PRRSV and PCV2 on pathogenesis in the infected pigs. PRRSV infection followed by PCV2 enhances the replication of viruses in piglets and results in more severe clinical signs and lesions [28]. In this study, PRRSV/PCV2 co-infected mouse model was established by inoculating PRRSV first, followed by PCV2 $2 \mathrm{~h}$ later through multiple routes (intraperitoneal, subcutaneous on back and intranasal injections). The results showed that both PRRSV and PCV2 could be detected in inguinal lymph nodes, spleen, liver, heart, lungs, kidneys and thymus at 7 
days of infection, indicating that both PRRSV and PCV2 could infect and spread in mice. qPCR was further used to determine whether the viruses have tissue specificity. The copy number of PRRSV N gene was less than 10, indicating that PRRSV could not replicate well in mice. PCV2 Cap gene copy numbers were highest in liver, followed by thymus and spleen both in PRRSV/PCV2 co-infected and PCV2 infected mice. Moreover, Cap gene copy number in PRRSV/PCV2 co-infected group was higher than that in PCV2 alone group. In addition, PRRSV/PCV2 co-infection induced sever lung lesion with more pulmonary hemorrhages, thickened alveoli septa and decreased alveolar space. These results indicated that although PRRSV did not replicate well in mice, could not only promote PCV2 replication, but also aggravate lung lesions in mice. Similar results have been reported in PRRSV/PCV2 co-infected piglets. Co-infection of PRRSV and PCV2 enhanced both PRRSV and PCV2 replication which induce more serious interstitial pneumonia $[27,28]$. Therefore, the PRRSV/PCV2 co-infection mouse model established in this study could be preliminary used to study the mechanism of PRRSV/PCV2 co-infection as well as evaluating the antiviral activities of a drug.

Co-infection of PRRSV and PCV2 increased the number of peritoneal macrophages and phagocytic function at 10 days post-infection, which may be related to the route of virus inoculation. Different inoculation routes may induce different immune responses. In this study, mice were inoculated with viruses partly by intraperitoneal injection, so a large number of macrophages were gathered to remove these viruses. In addition, virus co-infection also increased the spleen and thymus index, and spleen lymphocyte proliferation which indicated that co-infection activated the immune response. However, coinfection prolonged both the body weight gain ( $19 \mathrm{dpi}$ ) and the phagocytic capacity of peritoneal macrophages which continued to decrease at $13 \mathrm{dpi}$ and $16 \mathrm{dpi}$, indicating that the virus co-exist has eventually interfere with the body function. Pigs are less able to resist and eliminate secondary infectious agents due to the effect of PRRSV on the thymus [31]. The co-infection of PRRSV and PCV2 may aggravate this phenomenon.

Matrine with a dose of $40 \mathrm{mg} / \mathrm{kg}$ significantly decreased PCV2 Cap gene expression in liver both at 10 and $13 \mathrm{dpi}$, indicating that Matrine could inhibit PCV2 replication in mice. However, at 16 and $19 \mathrm{dpi}$, Matrine inhibited the Cap gene expression in varying degrees, but with no significant difference. The above results demonstrated that Matrine interfere the virus replication in the early stage of infection. During the study, it was found that $10 \mathrm{mg} / \mathrm{kg}$ Martine promote the continuous body weight gain. $40 \mathrm{mg} / \mathrm{kg}$ Martine increased lymphocytic proliferation index and enhanced the phagocytic ability of macrophages. These results indicated that Matrine could reduce the virus-induced lesions by enhancing the immune function. It has been reported that Astragalus polysaccharides inhibited PCV2 replication by inhibiting oxidative stress and blocking NF-KB pathway [18]. Our previous results showed that Matrine and scutellarin inhibited PCV2 infection in vitro [20]. Other researches also demonstrated that carboxymethylpachymaran, Glutamine and selenium yeast reduced the inflammatory response and pathological phenomenon induced by PCV2 though regulating the immune response, but had no effect on PCV2 replication [32-34]. 


\section{Conclusions}

PRRSV/PCV2 co-infection mouse model was established by inoculating PRRSV followed by PCV2 $2 \mathrm{~h}$ later through multiple routes including the intraperitoneal, subcutaneous on back and intranasal injections. Both PRRSV and PCV2 spread in mice, but only PCV2 replicates more efficiently. PRRSV infection promoted PCV2 replication and aggravated lungs lesions in mice. Matrine in a dose-dependent manner inhibited PCV2 replication in liver of mice co-infected by PRRSV/PCV2. $40 \mathrm{mg} / \mathrm{kg}$ Martine increased lymphocytic proliferation and enhanced the phagocytic ability of macrophages through regulating the immune function to reduce the virus-induced lesions.

\section{Abbreviations}

PRRSV

porcine reproductive and respiratory syndrome virus

PCV2

porcine circovirus type 2

Dpi

days post-infection

MFI

Median fluorescence intensity

FCS

fetal calf serum

SEM

standard errors of the mean

\section{Declarations}

\section{Ethics approval and consent to participate}

The experimental protocol was approved by the Bioethical Committee of the University of Shanxi Agricultural University.

\section{Consent for publication}

All authors critically revised the manuscript for important intellectual contents and approved the final manuscript.

\section{Availability of data and material}

The datasets analyzed in the present study are available from the corresponding author on reasonable request. 
The authors declare no competing financial interests.

\section{Funding}

This work was supported by National Key R\&D Program of China (Grant No. 2017YFD0501500), National Natural Science Foundation of China (Grant No. 31702285) and Shanxi Province Science Foundation for Excellent Youths (Grant No. 201801D211003).

\section{Author contributions}

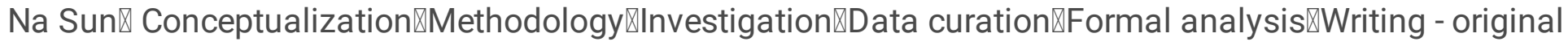
draft囚Funding acquisition

Hua Zhang $\$ Investigation $₫$ Data curation $\otimes$ Formal analysis $₫$ Visualization $₫$ Writing - original draft

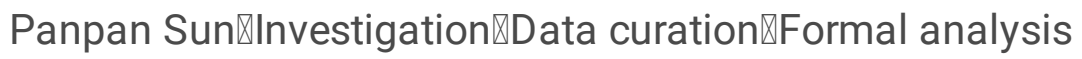

Ajab Khan: Writing - review \& editing $₫$ Visualization

Jianhua Guo $₫$ Writing - review \& editing $₫$ Visualization

Xiaozhong Zheng $₫$ Writing - review \& editing $₫$ Visualization

Yaogui Sun $₫$ Validation $₫$ Resources $₫$ Supervision

Kuohai Fan®Resources $₫$ Supervision

Wei Yin $\$ Resources $\$ Supervision

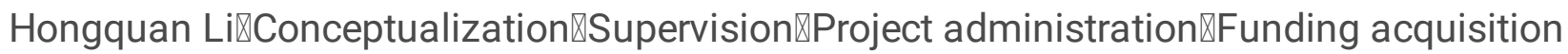

\section{Acknowledgements}

We thank Ping Jiang and Shaobo Xiao for their skillful technical support.

\section{References}

1. Chen NH, Huang YC, Ye MX, Li S, Xiao YZ, Cui BL, et al. Co-infection status of classical swine fever virus (CSFV), porcine reproductive and respiratory syndrome virus (PRRSV) and porcine circoviruses (PCV2 and PCV3) in eight regions of China from 2016 to 2018. Infect Genet Evol. 2019;68:127-35.

2. Oh T, Park KH, Yang S, Jeong J, Kang I, Park C, et al. Evaluation of the efficacy of a trivalent vaccine mixture against a triple challenge with Mycoplasma hyopneumoniae, PCV2, and PRRSV and the efficacy comparison of the respective monovalent vaccines against a single challenge. BMC Vet Res. 2019;15:342. 
3. Niederwerder MC, Bawa B, Serão NVL, Trible BR, Kerrigan MA, Lunney JK, et al. Vaccination with a porcine reproductive and respiratory syndrome (PRRS) modified live virus vaccine followed by challenge with PRRS virus and porcine circovirus type 2 (PCV2) protects against PRRS but enhances PCV2 replication and pathogenesis compared to results for nonvaccinated cochallenged controls. Clin Vaccine Immunol. 2015;22:1244-54.

4. Hakobyan A, Arabyan E, Avetisyan A, Abroyan L, Hakobyan L, Zakaryan H. Apigenin inhibits African swine fever virus infection in vitro. Arch Virol. 2016;161:3445-53.

5. Jie C, Luo Z, Chen H, Wang M, Yan C, Mao ZF, et al. Indirubin, a bisindole alkaloid from Isatis indigotica, reduces $\mathrm{H} 1 \mathrm{~N} 1$ susceptibility in stressed mice by regulating MAVS signaling. Oncotarget. 2017;8:105615-29.

6. Ma X, Guo Z, Zhang Z, Li X, Wang X, Liu Y, et al. Ferulic acid isolated from propolis inhibits porcine parvovirus replication potentially through Bid-mediate apoptosis. Int Immunopharmacol. 2020;83:106379.

7. Sun N, Sun PP, Xie N, Khan A, Sun YG, Fan KH, et al. Antiviral and immunomodulatory effects of Dipotassium Glycyrrhizinate in chicks artificially infected with Infectious Bursal Disease Virus. Pak Vet J. 2019;39:43-8.

8. Wang J, Sun PP, Feng YN, Guo JH, Sun YG, Lei HM, et al. Sodium tanshinone IIA sulfonate affects Marek's disease virus replication by inhibiting gB expression. Pharm Biol. 2016;54:701-4.

9. Zhang JQ, Gu YL, Wu CH, Ma HL, He JP, Bai YS, et al. Effects of sodium tanshinone IIA sulfonate against Marek's diseasevirus in experimentally infected chickens. Int J Biol Macromol. 2013;58:25862.

10. Yu ZQ, Yi HY, Ma J, Wei YF, Cai MK, Li Q, et al. Ginsenoside Rg1 Suppresses Type 2 PRRSV Infection via NF-KB Signaling Pathway In Vitro, and Provides Partial Protection against HP-PRRSV in Piglet. Viruses. 2019;11:1045.

11. Sun N, Sun PP, Yao MJ, Khan A, Sun YG, Fan KH, et al. Autophagy involved in anti-viral activity of Sodium tanshinone IIA sulfonate against porcine reproductive and respiratory syndrome virus (PRRSV) infection in vitro. Antivir Ther. 2019;24:27-33.

12. Li E, Sun N, Zhao JX, Sun YG, Huang JG, Lei HM, et al. In vitro evaluation of antiviral activity of tea seed saponins against porcine reproductive and respiratory syndrome virus. Antivir Ther. 2015;20:743-52.

13. Wang ZW, Sun N, Wu CH, Jiang JB, Bai YS, Li HQ. In vitro antiviral activity of Dipotassium Glycyrrhetate against porcine reproductive and respiratory syndrome virus. Antivir Ther. 2013;18:997-1004.

14. Liu XW, Bai J, Jiang CL, Song ZB, Zhao YX, Nauwynck H, et al. Therapeutic effect of Xanthohumol against highly pathogenic porcine reproductive and respiratory syndrome viruses. Vet Microbiol. 2019;238:108431.

15. Chen HL, Tan HL, Yang J, Song ML, Feng HY, Kuang N, et al. Inhibitory effect of polysaccharide of Sargassum weizhouense on PCV2 induced inflammation in mice by suppressing histone acetylation. 
Biomed Pharmacother. 2019;112:108741.

16. Li JR, Song DF, Wang SN, Dai YD, Zhou JY, Gu JY. Antiviral Effect of Epigallocatechin Gallate via Impairing Porcine Circovirus Type 2 Attachment to Host Cell Receptor. Viruses. 2020;12:176.

17. Yang HF, Chen XL, Jiang CM, He KW, Hu YY. In vivo Antiviral and Immunoregulatory Role Against PCV2 of Chinese Herbal Medicinal Ingredients. J Vet Res. 2017;61:405-10.

18. Xue H, Gan F, Zhang Z, Hu J, Chen X, Huang K. Astragalus polysaccharides inhibits PCV2 replication by inhibiting oxidative stress and blocking NF-KB pathway. Int J Biol Macromol. 2015;81:22-30.

19. Sun N, Wang ZW, Wu CH, Li E, He JP, Wang SY, et al. Antiviral activity and underlying molecular mechanisms of Matrine against porcine reproductive and respiratory syndrome virus in vitro. Res Vet Sci. 2014;96:323-7.

20. Sun N, Yu T, Zhao JX, Sun YG, Jiang JB, Duan ZB, et al. Antiviral activities of natural compounds derived from traditional Chinese medicines against Porcine Circovirus Type 2 (PCV2). Biotechnol Bioproc E. 2015;20:180-7.

21. Sun N, Sun PP, Lv HP, Sun YG, Guo JH, Wang ZR, et al. Matrine displayed antiviral activity in porcine alveolar macrophages co-infected by porcine reproductive and respiratory syndrome virus and porcine circovirus type 2. Sci Rep-UK. 2016;6:24401.

22. Rosenfeld P, Turner PV, Maclnnes JI, Nagy Éva Y, Dongwan. Evaluation of porcine reproductive and respiratory syndrome virus replication in laboratory rodents. Can J Vet Res. 2009;73:313-8.

23. Kiupel M, Stevenson GW, Choi J, Latimer KS, Kanitz CL, Mittal SK. Viral replication and lesions in $\mathrm{BALB} / \mathrm{c}$ mice experimentally inoculated with porcine circovirus isolated from a pig with postweaning multisystemic wasting disease. Vet Pathol. 2001;38:74-82.

24. Cságola A, Cadar D, Tuboly T. Replication and transmission of porcine circovirus type 2 in mice. Acta Vet Hung. 2008;56:421-7.

25. Li J, Yuan XY, Zhang CF, Miao L, Wu J, Shi J, et al. A mouse model to study infection against porcine circovirus type 2: viral distribution and lesions in mouse. Virol J. 2010;7:158.

26. Deng ZB, Wang ND, Xu DJ, Yan AW, Ge M, Luo W, et al. Viral distribution and lesions in Kunming mice experimentally infected with porcine circovirus type 2b. Vet Res Commun. 2011;35:181-92.

27. Rovira A, Balasch M, Segalés J, García L, Plana-Durán J, Rosell C, et al. Experimental inoculation of conventional pigs with porcine reproductive and respiratory syndrome virus and porcine circovirus 2. J Virol. 2002;76:3232-9.

28. Fan PH, Wei YW, Guo HL, Wu H, Huang L, Liu J, et al. Synergistic effects of sequential infection with highly pathogenic porcine reproductive and respiratory syndrome virus and porcine circovirus type 2. Virol J. 2013;10:265.

29. Xiu FM, Stanojcic M, Jeschke MG. Norepinephrine inhibits macrophage migration by decreasing CCR2 expression. Plos One. 2013;8:e69167.

30. Wang XQ, Duan XM, Liu LH, Fang YQ, Tan Y. Carboxyfluorescein diacetate succinimidyl ester fluorescent dye for cell labeling. Acta Biochim Biophys Sin (Shanghai). 2005;37:379-85. 
31. Wang G, Yu Y, Cai XH, Zhou EM, Zimmerman JJ. Effects of PRRSV infection on the porcine thymus. Trends Microbiol. 2020;28:212-23.

32. Wei YY, Hu TJ, Su ZJ, Zeng Y, Wei XJ, Zhang SX. Immunomodulatory and antioxidant effects of carboxymethylpachymaran on the mice infected with PCV2. Int J Biol Macromol. 2012;50:713-9.

33. Ren WK, Li YH, Yu XL, Luo W, Liu G, Shao H, et al. Glutamine modifies immune responses of mice infected with porcine circovirus type 2. Brit J Nutr. 2013;110:1053-60.

34. Liu G, Yang G, Guan GP, Zhang Y, Ren W, Yin J, et al. Effect of dietary selenium yeast supplementation on porcine circovirus Type 2 (PCV2) infections in mice. PLoS One. 2015;10:e0115833.

\section{Figures}

Fig. 1
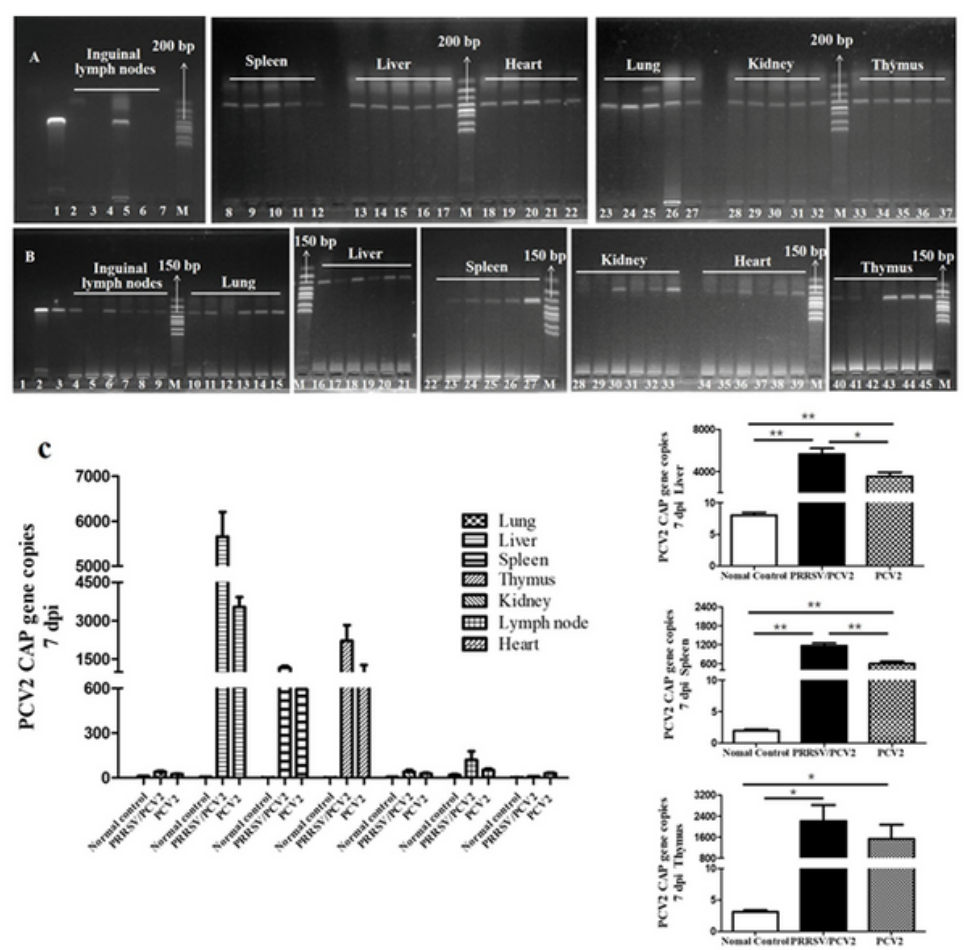

\section{Figure 1}

Agarose gel electrophoresis of PCR products of PRRSV N gene (A) and PCV2 CAP gene (B) PCR products in tissues from PRRSV/PCV2 co-infected mice. The products size of PRRSV N gene and PCV2 CAP gene were 196 bp and 148 bp respectively. M means Marker; 1: negative control; 2 ( $A$ and B): positive control; 3 (B): positive control. C: The distribution of PCV2 in both PRRSV/PCV2 co-infected mice and PCV2 alone infected mice at $7 \mathrm{dpi}$ by qPCR assay. Data were expressed as mean $\pm S E M$. *means $p<0.05$, ** means $p<0.01, * \star \star$ means $p<0.001$. 
Fig. 2
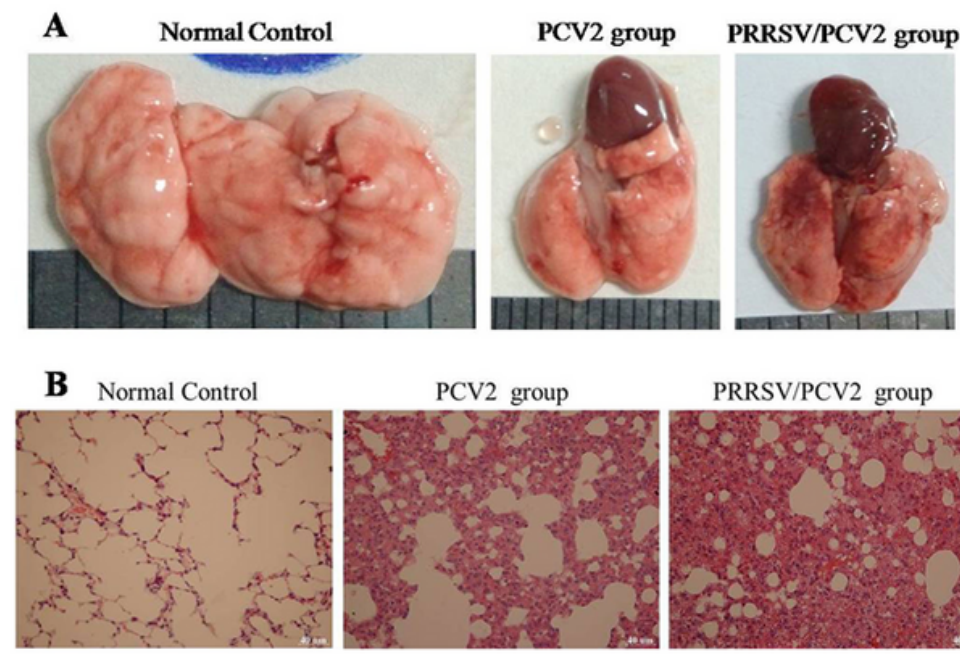

PRRSV/PCV2 group

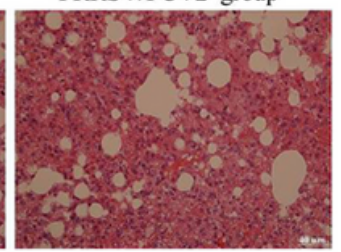

\section{Figure 2}

Lung morphological observation and H\&E histology in normal and infected mice. No lung lesions in normal control group. Obvious lesions were observed in lungs of both PRRSV/PCV2 co-infected and PCV2 infected mice (A). Hemorrhages and typical characteristics of interstitial pneumonia including thickened alveoli septa and decreased alveolar spaces were displayed both in PRRSV/PCV2 co-infected and PCV2 infected mice from the results of H\&E staining (B). Compared with PCV2 infected group, the lungs lesions were much severe in PRRSV/PCV2 co-infected group. 
Fig. 3

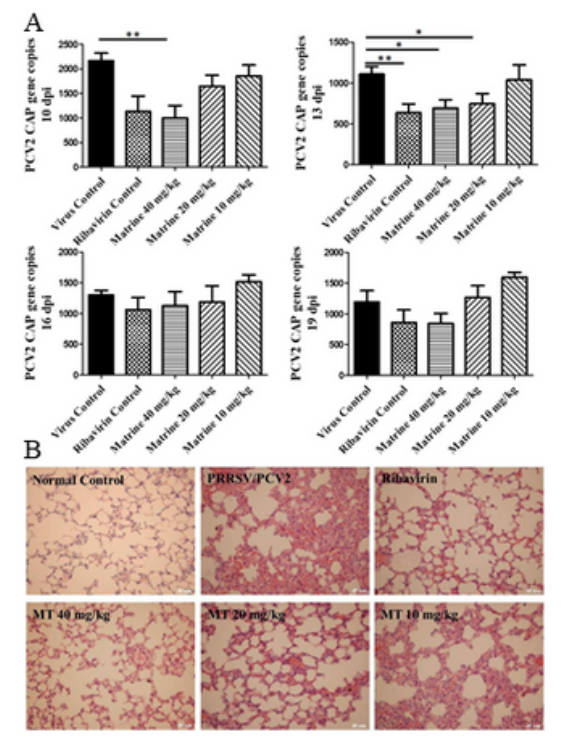

\section{Figure 3}

Matrine restrained $P C V 2$ replication in liver $(A)$ and alleviation of virus-induced lung lesions (B). A: Effect of Matrine on PCV2 CAP gene expression in liver at 10, 13, 16 and 19 dpi. qPCR results demonstrated that Matrine significantly inhibited PCV2 CAP gene expression both at 10 and $13 \mathrm{dpi}$. Data were expressed as mean \pm standard errors mean (SEM). * means $p<0.05$, ** indicates $p<0.01$, *** means $p<0.001$. B: H\&E staining demonstrated that compared with normal control, PRRSV/PCV2 group displayed severe thickened alveoli septa and decreased alveolar space. While both Ribavirin treatment and Matrine treatments $(40 \mathrm{mg} / \mathrm{kg}$ and $20 \mathrm{mg} / \mathrm{kg}$ ) could significantly alleviate these pathological changes. Scale bar $=40 \mu \mathrm{m}$. 
Fig. 4

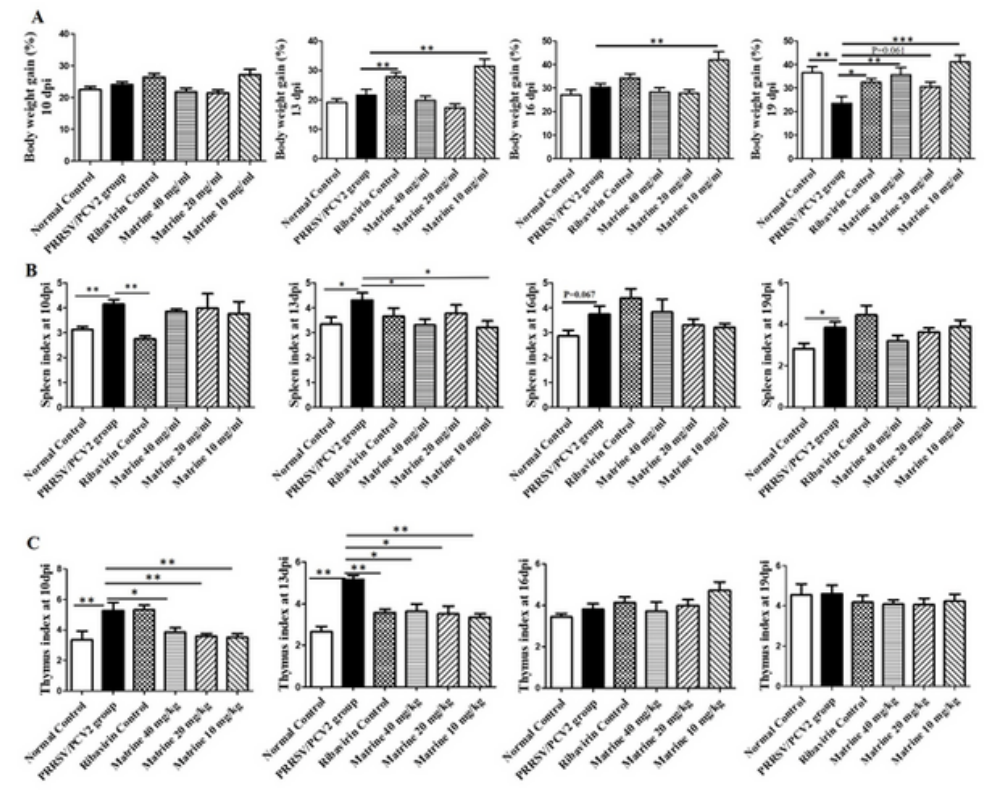

\section{Figure 4}

Effect of Matrine on body weight gain, spleen and thymus indices at 10,13, 16 and $19 \mathrm{~d}$ post-infection. Data were expressed as mean \pm standard errors mean (SEM). * means $p<0.05$, ** indicates $p<0.01$, *** means $p<0.001$. 
Fig. 5

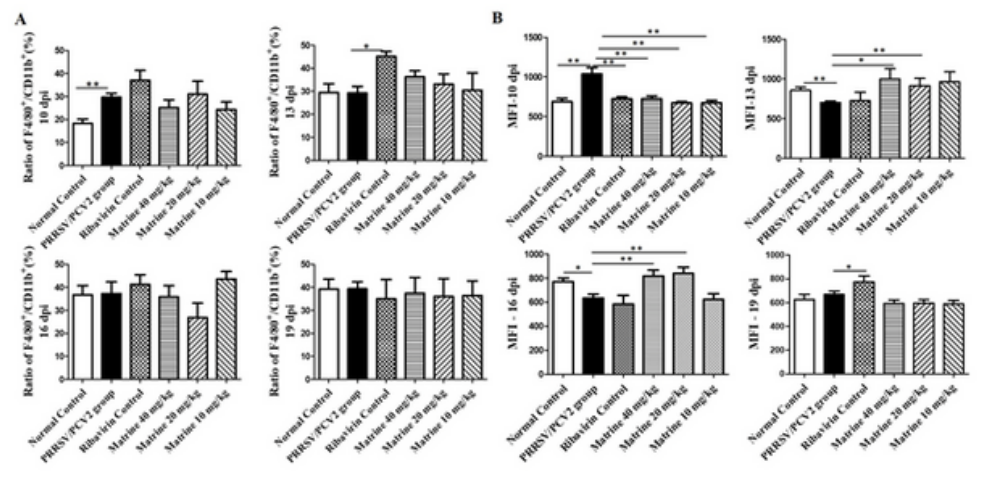

\section{Figure 5}

Effect of Matrine on the percentage of peritoneal macrophages and its phagocytic capacity in all the groups at $10,13,16$ and $19 \mathrm{dpi}$. The macrophages were labeled by both anti- $\mathrm{F} 4 / 80$ antibody and antiCD11b antibody. The ratio of F4/80+/CD11b+ was counted by flow cytometry. The capacity of phagocytosis was expressed by median fluorescence intensity (MFI). Data were expressed as mean \pm standard errors mean (SEM). * means $p<0.05$, ** indicates $p<0.01$, $* \star \star$ means $p<0.001$. 
Fig. 6

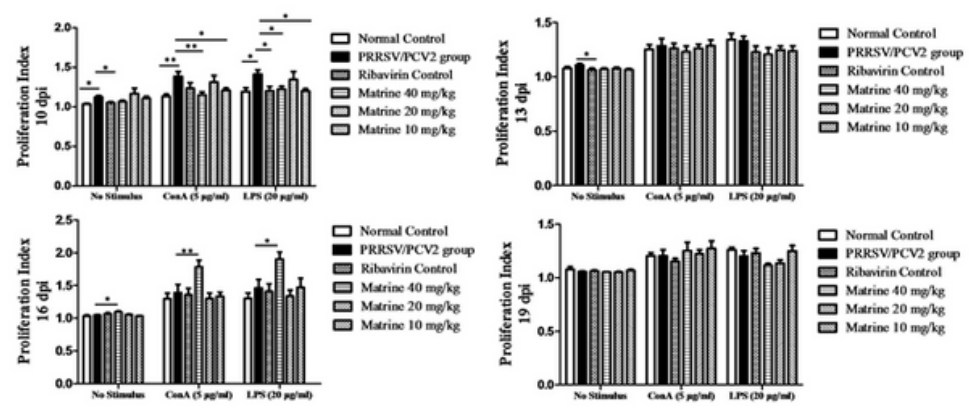

\section{Figure 6}

Effect of Matrine on proliferation of splenic lymphocytes at 10, 13, 16 and $19 \mathrm{dpi}$. After labeled by CFSE, Proliferation index of different treatment groups wererespectively detected by flow cytometry without or with ConA and LPS treatment. Data were expressed as mean \pm standard errors mean (SEM). * means $p$ $<0.05, * *$ indicates $p<0.01$, *** means $p<0.001$. 